\title{
Non-criteria Antiphospholipid Antibodies: a narrative review
}

\author{
(D)Andreas Funke \\ (D) Henrique Luiz Staub ${ }^{2}$ \\ (iD) Odirlei Andre Monticielo ${ }^{3}$ \\ (D) Gustavo Guimarães Moreira Balbi ${ }^{4}$ \\ (iD)Adriana Danowski ${ }^{5}$ \\ Dittermayer Barreto Santiago ${ }^{6}$ \\ (D)Danieli Castro Oliveira de Andrade \\ (iD) Jozelia Rêgo ${ }^{8}$
}

\begin{abstract}
1. Universidade Federal do Paraná (UFPR), Hospital de Clínicas, Serviço de Reumatologia, Curitiba, PR, Brasil. 2. Pontifícia Universidade Católica do Rio Grande do Sul (PUC-RS), Escola de Medicina, Serviço de Reumatologia, Porto Alegre, RS, Brasil. 3. Universidade Federal do Rio Grande do Sul (UFRGS), Departamento de Medicina Interna, Hospital de Clínicas de Porto Alegre (HCPA), Serviço de Reumatologia, Porto Alegre, RS, Brasil. 4. Universidade Federal de Juiz de Fora (UFJF), Hospital Universitário, Serviço de Reumatologia, Juiz de Fora, MG, Brasil. 5. Hospital Federal dos Servidores do Estado (HFSE), Serviço de Reumatologia, Rio de Janeiro, RJ, Brasil. 6. Universidade Federal da Bahia (Hupes) e Escola Baiana de Medicina e Saúde Pública, Salvador, BA, Brasil. 7. Universidade de São Paulo (USP), Divisão de Reumatologia, São Paulo, SP, Brasil.
\end{abstract}

8. Universidade Federal de Goiás (UFG), Faculdade de Medicina, Serviço de Reumatologia, Goiânia, GO, Brasil.

http://dx.doi.org/10.1590/1806-9282.66.11.1595

\section{SUMMARY}

The 2006 Revised Sapporo Classification Criteria for Definite Antiphospholipid Syndrome included as laboratory criteria the tests for antiphospholipid antibodies whose accuracy was regarded as satisfactory according to the evidence available at that time. In practice, however, the sensitivity and specificity of these "criteria" of antiphospholipid antibodies are sometimes insufficient for identifying or ruling out antiphospholipid syndrome. It has been studied whether the accuracy of the laboratory diagnosis of the syndrome could be improved by testing for non-criteria antiphospholipid antibodies. In this work, we review evidence on the clinical associations and diagnostic value of the most commonly studied non-criteria antibodies, namely: antiphosphatidylethanolamine, anti-annexin A5, antiprothrombin, anti-phosphatidylserine/prothrombin complex, IgA anticardiolipin, and IgG anti-domain I of the $\beta 2$ glycoprotein antibodies.

KEYWORDS: Antiphospholipid syndrome. Antibodies, Antiphospholipid. Thrombosis/diagnosis.

\section{INTRODUCTION}

According to the 2006 Sydney revision of the 1999 Sapporo criteria, the classification of antiphospholipid syndrome (APS) requires at least one of two clinical criteria: vascular thrombosis or pregnancy morbidity, along with laboratory evidence of the presence of moderate to high titers of IgG/IgM anticardiolipin antibodies (aCL) and/or anti- $\beta 2$-glycoprotein I antibodies (anti- $\beta 2$-GPI) and/or the presence of lupus anticoagulant (LA), on 2 or more occasions, at least 12 weeks apart ${ }^{1}$.

Antiphospholipid antibodies (aPL) are a heterogeneous group of autoantibodies directed against 
anionic phospholipids, phospholipid-binding plasma proteins, or phospholipid-protein complexes. Apart from the conventional laboratory markers of APS mentioned above, several other autoantibodies have been described, known as non-criteria aPL, which could help to diagnose patients with clinical manifestations of APS but who are negative for the traditional antibodies and may, therefore, present the so-called "seronegative APS" (SNAPS).

The purpose of this article is to review the main characteristics and clinical relevance of the major non-criteria aPL.

\section{METHODS}

Specialists from the Antiphospholipid Syndrome Committee of the Brazilian Society of Rheumatology reviewed the evidence on the clinical associations and relevance of the most commonly studied non-criteria aPL. Pubmed database was searched for original studies and prior reviews on non-criteria aPL published in English or Portuguese. Additional references were obtained by manually searching the available publications. Non-criteria aPL with a larger number of studies and/or greater potential routine-testing feasibility and clinical utility in the diagnosis of APS were selected by the authors for further review. Publications were reviewed for evidence on their clinical value in the assessment of patients with suspected or confirmed APS or patients with possible SNAPS. The available evidence was discussed and compiled by the authors.

\section{NON-CRITERIA APL}

Antiphosphatidylethanolamine antibodies

Phosphatidylethanolamine (PE), a neutral PL, is frequently the main lipid component of microbial membranes and is largely found in mitochondria. Antibodies against PE (aPE) were reported as the sole aPL in patients with thrombotic manifestations or pregnancy loss. However, screening for IgG, IgM, and IgA aPE did not increase the diagnostic yield for APS ${ }^{2}$ and, according to a 2010 report, aPE did not behave as an independent risk factor for further miscarriage in patients with pregnancy losses ${ }^{3}$. Nonetheless, aPE were the aPL with the highest odds ratio for thrombosis in a survey of 270 patients. Of major interest, $63 \%$ of the 40 aPE-positive patients were negative for conventional aPL 4 .
The value of aPE in patients with the so-called SNAPS is a very hot topic under investigation. In a 2012 study, thin-layer chromatography immunostaining revealed the presence of aPL in $58.3 \%$ of patients with SNAPS, being aPE documented in $30.5 \%$ of such cases ${ }^{5}$.

A comprehensive review of the aPE role in patients with thromboembolic events and pregnancy morbidity was published in $2012^{6}$. Thirty years after the original description of aPE antibodies in a patient with primary $\mathrm{APS}^{7}$, the role of aPE in individuals with unexplained thrombosis and pregnancy morbidity remains controversial.

\section{Anti-annexin A5 antibodies}

The relationship of anti-annexin A5 antibodies (aAnx A5) with thrombophilic states and pregnancy morbidity is a matter of debate. Circulating aAnx A5 has been described in APS, recurrent miscarriages, SLE (irrespective of APS), and sclerodermic digital ulcers and were also associated with thrombotic episodes in patients with SLE and $\mathrm{APS}^{8}$. In a 2006 survey of APS, SLE, and lupus-like patients, the presence aAnx A5 was not associated with thrombosis or miscarriages. The -1C-->T annexin A5 mutation, nevertheless, was an independent risk factor for miscarriages ${ }^{9}$. In practical terms, testing for aAnx A5 by ELISA still lacks standardization, and not rarely the IgM isotype is missing in studies.

In a more recent Egyptian study, the presence of the IgM aAnx A5 isotype was related to APS and recurrent pregnancy $\operatorname{loss}^{10}$. These data contrast with previous information showing a link between the IgG aAnx A5 isotype and pregnancy losses in patients with primary APS ${ }^{11}$. In 2016, it was suggested that adding the IgM aAnx A5 isotype to conventional aPL assays might be useful to detect APS subsets, as well as to evaluate the risk of thrombotic recurrence ${ }^{12}$. As a whole, testing both IgG and IgM aAnx A5 isotypes seems to be appropriate ${ }^{10-12}$.

Yet regarding pregnancy morbidity, a small group (23 cases) of obstetric APS with recurrent miscarriages was studied in 1999. The frequency of IgG and IgM aAnx A5 did not differ from controls ${ }^{13}$. In 2010, traditional aPL and aAnx A5 were analyzed in 54 women with spontaneous pregnancy loss. While LA was associated with early miscarriages and aCL with fetal losses, such linkages were not confirmed for aAnx A $5^{14}$.

In patients with primary APS, high IgM aAnx A5, and high IgM aCL correlated with pulmonary 
embolism, while the corresponding IgG isotypes were associated with cerebral arteriopathy ${ }^{15}$. More recent studies will probably clarify the role of aAnx A5 isotypes in different clinical subsets of APS.

In 112 patients with APS, high levels of aAnx A5 were documented as compared to controls ${ }^{16}$. In another interesting study, IgG aAnx A5 (not always coincident with LA or aCL) was found to be more frequent in patients with acute cerebral ischemia than controls ${ }^{17}$.

As a whole, few studies have addressed the prevalence of aAnx A5 in patients suspected of having APS. The majority of studies looked at their frequency in patients with confirmed aPL in conventional assays or proven APS. Moreover, most of these reports included a limited number of samples ${ }^{8-15}$.

Antibodies to Prothrombin and Phosphatidylserine/Prothrombin

Antibodies against prothrombin can be detected by ELISA either by using prothrombin-coated irradiated plates (aPT) or the phosphatidylserine/prothrombin (PS/PT) complex as the antigen. Although aPT and antibodies to PS/PT (aPS/PT) can coexist in the same patient, they appear to belong to different antibody populations ${ }^{18}$.

Several authors have evaluated the relationship between aPS/PT and APS. Atsumi et al. ${ }^{19}$ reported that aPS/PT, but not aPT, were associated with the clinical manifestations of APS in 265 patients with autoimmune diseases. In addition, IgG aPS/PT were strongly associated with the presence of LA. Tsutsumi et al. ${ }^{20}$ evaluated IgG aPT and IgG aPS/PT in comparison with each other and with IgG and IgM aCL, IgG $\beta 2 \mathrm{GPI}-d e p e n d e n t$ aCL and LA for their association with a history of thrombosis in 139 SLE patients and concluded that all these tests, except IgM aCL, are potentially useful in the evaluation of the thrombotic risk and that although aPT and aPS/PT correlate with each other, they are not completely identical.

Zigon et al. ${ }^{21}$ assessed the diagnostic value of IgG and IgM aPS/PT, tested by both an in-house assay and a commercial assay, in 156 patients with systemic autoimmune diseases. Both assays were highly concordant and IgG aPS/PT was the strongest independent risk factor for obstetric complications. IgG and IgM aPS/PT were associated with venous but not arterial thrombosis. In addition, there was a highly significant association between the presence of IgG/IgM aPS/PT and LA activity. The authors conclude that
aPS/PT detected by either assay represents a promising serological marker for APS ${ }^{21}$. Sanfelippo et al. ${ }^{22}$ reported the presence of aPS/PT in 41 of 728 serum specimens from patients suspected of having APS who were negative for aCL and anti- $\beta 2$ GPI. Of note, among 22 patients with available medical records, 11 had a history of thrombosis. The authors suggest that aPS/ PT could contribute to the diagnosis of APS in patients who present negative tests for conventional aPL.

Fabris et al. ${ }^{23}$ evaluated the impact of aPS/PT testing in the first 6 months after its introduction in a clinical laboratory practice. IgG and/or IgM aPS/PT were present in 49 (11.6\%) of 421 patients selected for having a medical order for this test. In addition, aPS/ PT were more frequent in LA-positive than in LA-negative patients ( $56.1 \%$ vs. $6.4 \%$, respectively). aPS/PT were also more prevalent than aPT in a retrospective analysis of 52 LA-positive patients (55.8\% vs. $15.4 \%$, respectively). Finally, aPS/PT were detected in about $27 \%$ of the patients with LA results that were difficult to interpret. The authors recommend the introduction of aPS/PT in the APS diagnostic process and suggest that these antibodies may be useful when the correct interpretation of LA testing is precluded by the use of oral anticoagulants ${ }^{23}$. In a systematic review of the available evidence on aPT and aPS/PT and the risk of thrombosis in APS, Sciascia et al. ${ }^{24}$ found that aPS/PT were more strongly associated with venous and/or arterial thrombosis than aPT (OR 5.11 [95\% C.I. 4.2-6.3] vs. 1.82 [95\% C.I. 1.44-2.75], respectively) and suggested that the routine measurement of aPS/ PT, but not of aPT, might be useful in assessing the thrombotic risk in patients with previous thrombosis or with SLE ${ }^{24}$.

Zigon et al. ${ }^{25}$ reported a positive IgG or IgM aPS/ PT test in 22 (13\%) of 169 patients with APS-related obstetric manifestations. Of note, aPS/PT was the only aPL detected in 11 (6.5\%) of those patients and the only aPL associated with recurrent early pregnancy loss. In this study, aPS/PT were associated with early or late pregnancy loss and with prematurity independently from other $\mathrm{aPL}^{25}$. Amengual et al. ${ }^{26}$ reported the results of an international multicentric study and a subsequent validation study evaluating two IgG aPS/ PT ELISA kits for the diagnosis of APS. There was an acceptable agreement between the results of both kits and the presence of IgG aPS/PT was associated with arterial and venous thrombosis (initial and validation studies) and obstetric (initial study only) manifestations of APS. According to the authors, IgG aPS/PT 
should be considered for inclusion as an additional laboratory criterion for the classification of APS $^{26}$.

Nakamura et al. ${ }^{27}$ retrospectively assessed the value of the combined use of tests for anti-DI and IgG/ IgM aPS/PT for the diagnosis of APS in a group of 157 patients. Twenty-one patients were positive for both antibodies and presented an elevated antiphospholipid score (APL-S). Of the 14 patients who were positive for aPS/PT and negative for anti-DI, 11 (79\%) had APS and high APL-S values. The authors conclude that the first-line use of the combination of these two tests may contribute to the identification of patients with APS and high risk of thrombosis ${ }^{27}$.

Litvinova et al..$^{28}$ assessed the prevalence and significance of non-conventional aPL, including IgG/IgM aPS/PT, aPE, aAnx A5, IgA anti- $\beta 2$ GPI and IgG anti-DI, in a prospective cohort of patients with APS, SNAPS, asymptomatic aPL carriers or presenting with a first thrombotic or obstetric event. The number of positive non-conventional tests increased with the severity of APS, and aPS/PT were significantly associated with the clinical manifestations of APS and with the presence of LA. All patients who were triple-positive for the conventional aPL showed persistent aPS/PT positivity. The authors conclude that aPS/PT are of potential value as strong markers of APS and propose the use of these antibodies for risk stratification in patients in whom LA cannot be detected because of ongoing treatment with direct oral anticoagulants ${ }^{28}$.

In a recent study, Zigon et al..$^{29}$ evaluated the added value of some non-criteria aPL for the diagnosis of APS and found an association between IgA aCL, IgA anti- $\beta 2 \mathrm{GPI}$, and IgG/IgA aPS/PT and thrombosis, and between IgA aCL, IgA anti- $\beta 2$ GPI, and IgG/IgM/IgA aPS/PT and obstetric events. Interestingly, among these non-criteria aPL, only aPS/PT were detected in isolation, being positive in $3 \%$ of the seronegative patients with thrombosis and $2 \%$ of the seronegative patients with pregnancy morbidity ${ }^{29}$.

\section{$\lg \mathrm{A}$ anticardiolipin and $\lg \mathrm{A}$ anti- $\beta 2$ glycopro- tein I antibodies}

Patients with IgA aPL may present classical APS clinical manifestations such as thrombotic events and pregnancy morbidity as well as non-criteria manifestations such as livedo, skin ulcers, Raynaud's phenomenon, cognitive dysfunction, epilepsy, thrombocytopenia, and heart valve disease ${ }^{30}$. Notwithstanding, neither IgA aCL nor IgA anti- $\beta 2$ GPI antibodies were included in the revised Sapporo criteria for the classification of APS, possibly because of insufficient evidence and/or sub-optimal assay standardization ${ }^{1,30}$.

IgA aCL antibodies are present in up to $38 \%$ of the patients with APS and in up to $16 \%$ of the patients with SLE $^{31}$. IgA anti- $\beta 2$ GPI antibodies, in turn, can be detected in up to $56.3 \%$ of the APS patients and in up to $30.4 \%$ of SLE patients ${ }^{31,32}$. While isolated IgA aCL positivity is very infrequent ${ }^{1,30}$, isolated IgA anti$\beta 2 \mathrm{GPI}$ antibodies are detected in 3.9 to $7.9 \%$ of SLE patients $^{33}$ and in up to $10.6 \%$ of the patients with clinical features of APS but negative testing for the criteria aPL (SNAPS) ${ }^{34}$. A significant association between isolated IgA anti- $\beta 2$ GPI antibodies and thrombosis, particularly in the arterial bed, has been reported in SLE patients ${ }^{30,33}$. These patients may also develop pregnancy loss or present non-criteria manifestations of $\mathrm{APS}^{33}$.

Despite the confirmed clinical relevance of IgA anti$\beta 2$ GPI antibodies, particularly among SLE patients, and their potential utility as additional prognostic indicators in confirmed APS or as diagnostic markers in SNAPS, their testing may still be poorly standardized with wide variations in testing methodology and diagnostic accuracy of commercially available laboratory kits.

\section{Anti- $\beta 2$ glycoprotein I Domain I antibodies}

The revised Sapporo criteria for the classification of APS include persistent moderate-to-high titers of IgG and IgM anti- $\beta 2$ GPI antibodies. However, because thrombosis-associated anti- $\beta 2$ GPI antibodies are mainly those directed against an epitope located at domain I (DI) of $\beta 2 \mathrm{GPI}$, aPL testing based on the whole $\beta 2$ GPI molecule might be insufficiently specific for the clinical manifestations of the syndrome ${ }^{1,35}$. IgG anti-DI occurs in up to $73.2 \%$ of the patients with APS, up to $26.7 \%$ of the SLE patients without thrombosis, and up to $11.1 \%$ of asymptomatic aPL carriers ${ }^{36,37}$.

According to the results of two systematic reviews of the literature, the presence of IgG anti-DI antibodies doubles the risk of thrombosis in patients with $\mathrm{APS}^{32,37}$. Anti-DI antibodies are very specific markers of APS (specificity above 97\%), particularly in patients with thrombosis ${ }^{38}$.

The usefulness and cost-effectiveness of adding anti-DI testing to the classical ("criteria") aPL panel have been questioned by some authors, since some conventional anti- $\beta 2$ GPI assays may already offer sensitivity and specificity at least similar to that of anti-DI antibodies ${ }^{31,39}$. 
Given that clinical practice testing for the laboratory criteria for APS, particularly for LA, suffers from poor standardization and reproducibility, an interesting approach has been proposed, namely, to make first-line use of the combination of anti-DI with aPS/PT antibody testing, which in one study conveyed very high positive predictive values and acceptable sensitivity for $\mathrm{APS}^{27}$. Should these findings be confirmed in subsequent studies, this would be a very interesting and cost-effective application of anti-DI antibody testing.

\section{DISCUSSION AND CONCLUSIONS}

Laboratory testing for aPL still consists of different and poorly standardized assays, and their clinical associations are still mostly derived from studies with a retrospective design and wide variation in sample sizes. An overview of the clinical significance and limitations of non-criteria aPL tests is shown in Table 1.

While there is no robust evidence to propose the inclusion of aPE antibodies as criteria for APS, one should not neglect the importance of testing for aPE in cases of SNAPS. Whether or not patients with sole aPE and thrombosis should be classified in the long term as having "true" APS is another question to be addressed in the future.
An association of IgG and/or IgM aAnx A5 with thrombotic or obstetric APS is not substantiated by current data, and eventual incorporation of these antibodies to APS criteria is not justified at the moment. Nevertheless, occasional testing of aAnx A5 in aPL-negative patients suspected of APS, mainly obstetric or neurologic, is a field open to discussion.

aPS/PT, but not aPT, can significantly improve the recognition of patients with APS in clinical practice and serve as a laboratory marker for the risk of thrombotic events and pregnancy morbidity, including early pregnancy loss. In addition, aPS/PT, detected by solid-phase assays, can be a surrogate marker of the presence of LA in the setting of oral anticoagulant therapy which impairs the interpretation of functional coagulation assays.

Patients with SLE and patients suspected of having APS (with or without SLE) should be tested for IgA anti- $\beta 2$ GPI using standardized/validated assays, either as part of the initial aPL workup ("first line") or as a follow-up test if criteria aPL are negative. Testing for IgA aCL does not seem to provide substantial diagnostic value because their isolated positivity is infrequent.

Despite their proven role in APS pathogenesis and potentially higher specificity for the thrombotic manifestations of APS, IgG anti-DI antibodies do not consistently improve diagnostic accuracy beyond

TABLE 1. NON-CRITERIA APL CLINICAL EVIDENCE OVERVIEW AND WORKGROUP CONCLUSIONS

\begin{tabular}{|c|c|c|c|c|}
\hline Test & Clinical significance ${ }^{*}$ & Main Limitations & $\begin{array}{l}\text { Eligible to be added } \\
\text { to APS classification } \\
\text { criteria? }\end{array}$ & $\begin{array}{l}\text { Eligible for SNAPS } \\
\text { workup? }\end{array}$ \\
\hline aPE & $\begin{array}{l}\text { Association with thrombosis and gestational } \\
\text { morbidity }\end{array}$ & $\begin{array}{l}\text { Insufficient assay standardiza- } \\
\text { tion; inconsistent clinical value of } \\
\text { isolated aPE }\end{array}$ & No & Controversial \\
\hline aAnx A5 & $\begin{array}{l}\text { Association with neurologic events and } \\
\text { gestational morbidity }\end{array}$ & $\begin{array}{l}\text { Insufficient assay standardization; } \\
\text { inconsistent clinical value }\end{array}$ & No & No \\
\hline aPT & $\begin{array}{l}\text { Association with thrombosis/pregnancy } \\
\text { morbidity }\end{array}$ & $\begin{array}{l}\text { Weaker association with thrombo- } \\
\text { sis than that of aPS/PT }\end{array}$ & $\begin{array}{l}\text { No } \\
\text { (aPS/PT preferred) }\end{array}$ & $\begin{array}{l}\text { No } \\
\text { (aPS/PT preferred) }\end{array}$ \\
\hline aPS/PT & $\begin{array}{l}\text { Positivity, even if isolated, is associated } \\
\text { with thrombosis and gestational morbidity; } \\
\text { association with severe APS }\end{array}$ & Paucity of prospective studies & $\begin{array}{l}\text { Yes }^{\star *} \text { (if LA detection is } \\
\text { not feasible) }\end{array}$ & Yes \\
\hline $\lg A$ aCL & Association with APS clinical manifestations & $\begin{array}{l}\text { Almost always accompanied by } \\
\text { criteria aPL; insufficient assay } \\
\text { standardization }\end{array}$ & No & Controversial \\
\hline $\begin{array}{l}\lg A \text { an- } \\
\text { ti- } \beta 2 G P \mid\end{array}$ & $\begin{array}{l}\text { Positivity, even if isolated, is associated with } \\
\text { thrombosis and pregnancy loss, particularly } \\
\text { in patients with SLE }\end{array}$ & $\begin{array}{l}\text { Prevalence/clinical associations } \\
\text { less studied in non-SLE popula- } \\
\text { tions }\end{array}$ & Yes & Yes \\
\hline Anti-DI & $\begin{array}{l}\text { Elevated specificity and positive predictive } \\
\text { value for thrombotic APS. }\end{array}$ & $\begin{array}{l}\text { Low rate of isolated positivity (e.g. } \\
\text { when criteria aPL are negative). }\end{array}$ & $\mathrm{No}^{\star *}$ & No \\
\hline
\end{tabular}

aPE: antiphosphatidylethanolamine antibodies; aAnx A5: antibodies to Annexin A5; aPT: antiprothrombin antibodies; aPS/PT: antibodies to the phosphatidylserine/prothrombin complex; IgA: Immunoglobulin A; aCL: anticardiolipin antibodies; anti- $\beta 2 \mathrm{GPI}$ : antibodies to $\beta 2$-glycoprotein I; anti-DI: antibodies to Domain I of $\beta 2$-glycoprotein I *According to available evidence, e.g., mostly retrospective and/or cross-sectional studies and systematic literature reviews of those studies ** First-line simplified APS workup with combined aPS/PT and anti-DI awaits further study 
conventional aPL testing. Moreover, IgG Anti-DI do not appear to increase the diagnostic yield in patients with suspected SNAPS because these patients are, by definition, IgG anti- $\beta 2$ GPI negative. Therefore, routine anti-DI antibody testing adds little additional value to criteria aPL testing in suspected or confirmed APS patients.

The first-line combination of anti-DI and aPS/PT testing may provide a simplified and reliable route for diagnosis of APS; however, more study is required before this strategy can be routinely recommended.

In patients with clinical manifestations of APS but with negative classical criteria aPL antibodies (i.e. SNAPS), the most promising non-criteria tests are IgA anti- $\beta 2 \mathrm{GPI}$ and IgG/IgM aPS/PT.

\section{Author's Contribution}

All authors have contributed equally to this work.

\section{RESUMO}

A classificação de Sapporo revisada para a síndrome antifosfolipídica definida de 2006 incluiu como critérios laboratoriais aqueles testes para anticorpos antifosfolípides cuja acurácia era considerada satisfatória de acordo com a evidência então disponível. Porém, na prática, a sensibilidade e especificidade desses anticorpos antifosfolípides "critério" são por vezes insuficientes para identificar ou descartar a síndrome antifosfolípide. Tem-se estudado se a acurácia do diagnóstico laboratorial da síndrome poderia ser melhorada por meio da testagem de anticorpos antifosfolípides não critério. Neste trabalho revisamos a evidência a respeito das associações clínicas e valor diagnóstico dos anticorpos não critério mais estudados, nomeadamente: anticorpos antifosfatidiletanolamina, antianexina A5, antiprotrombina, anticomplexo fosfatidilserina/protrombina, IgA anticardiolipina e lgG antidomínio I da anti- $\beta 2$ glicoproteína I.

PALAVRAS-CHAVE: Síndrome antifosfolipídica. Anticorpos antifosfolipídeos. Trombose/diagnóstico.

\section{REFERENCES}

1. Miyakis S, Lockshin MD, Atsumi T, Branch DW, Brey RL, Cervera R, et al. International consensus statement on an update of the classification criteria for definite antiphospholipid syndrome (APS). J Thromb Haemost. 2006;4(2):295-306.

2. Bertolaccini ML, Roch B, Amengual $O$, Atsumi T, Khamashta MA, Hughes GR. Multiple antiphospholipid tests do not increase the diagnostic yield in antiphospholipid syndrome. Br J Rheumatol. 1998;37(11):1229-32.

3. Obayashi S, Ozaki Y, Sugi T, Kitaori T, Katano K, Suzuki S, et al. Antiphosphatidylethanolamine antibodies might not be an independent risk factor for further miscarriage in patients suffering recurrent pregnancy loss. J Reprod Immunol. 2010;85(2):186-92.

4. Sanmarco M, Gayet S, Alessi MC, Audrain M, de Maistre E, Gris JC, et al. Antiphosphatidylethanolamine antibodies are associated with an increased odds ratio for thrombosis. A multicenter study with the participation of the European Forum on antiphospholipid antibodies. Thromb Haemost. 2007:97(6):949-54

5. Conti F, Alessandri C, Sorice M, Capozzi A, Longo A, Garofalo T, et al. Thinlayer chromatography immunostaining in detecting anti-phospholipid antibodies in seronegative anti-phospholipid syndrome. Clin Exp Immunol. 2012;167(3):429-37.

6. Staub HL, Bertolaccini ML, Khamashta MA. Anti-phosphatidylethanolamine antibody, thromboembolic events and the antiphospholipid syndrome. Autoimmun Rev. 2012;12(2):230-4.

7. Staub HL, Harris EN, Khamashta MA, Savidge G, Chahade WH, Hughes GR. Antibody to phosphatidylethanolamine in a patient with lupus anticoagulant and thrombosis. Ann Rheum Dis. 1989;48(2):166-9.

8. Satoh A, Suzuki K, Takayama E, Kojima K, Hidaka T, Kawakami M, et al. Detection of anti-annexin IV and $V$ antibodies in patients with antiphospholipid syndrome and systemic lupus erythematosus. J Rheumatol. 1999;26(8):1715-20.

9. de Laat B, Derksen RH, Mackie IJ, Roest M, Schoormans S, Woodhams BJ, et al. Annexin A5 polymorphism (-1C-->T) and the presence of anti-annexin A5 antibodies in the antiphospholipid syndrome. Ann Rheum Dis. 2006;65(11):1468-72.

10. Nasef A, Ibrahim M, Riad N, Mousa S. Plasma annexin A5, anti-annexin A5 antibodies and annexin A5 polymorphism in Egyptian female patients with systemic lupus erythematosus and antiphospholipid syndrome. Clin Lab. 2014;60(1):133-7.
11. Bećarević $M$. The lgG and lgM isotypes of anti-annexin $A 5$ antibodies: relevance for primary antiphospholipid syndrome. J Thromb Thrombolysis. 2016:42(4):552-7.

12. Bećarević M, Stojanović L, Ignjatović S, Dopsaj V. The IgM isotype of anti-annexin A5 antibodies and multiple positivity of conventional antiphospholipid antibodies: increasing the number of clinical manifestations of primary antiphospholipid syndrome. Clin Rheumatol. 2016;35(5):1361-5.

13. Siaka C, Lambert M, Caron C, Amiral I, Hachulla E, Hatron PY, et al. Low prevalence of anti-annexin $V$ antibodies in antiphospholipid syndrome with fetal loss. Rev Med Interne. 1999;20(9):762-5.

14. Alijotas-Reig J, Ferrer-Oliveras R, Rodrigo-Anoro MJ, Farran-Codina I, Llurba-Olivé E, Vilardell-Tarres $\mathrm{M}$, et al. Anti-annexin A5 antibodies in women with spontaneous pregnancy loss. Med Clin (Barc). 2010;134(10):433-8.

15. Bećarević M, Ignjatović $S$, Majkić-Singh N. Deterioration of thromboses in primary antiphospholipid syndrome: TNF-alpha and anti-annexin A5 antibodies. Clin Lab. 2012;58(9-10):1079-84.

16. Singh NK, Yadav DP, Gupta A, Singh U, Godara M. Role of anti-annexin A5 in pathogenesis of hypercoagulable state in patients with antiphospholipid syndrome. Int J Rheum Dis. 2013;16(3):325-30.

17. Lee $\mathrm{KO}, \mathrm{Kim}$ W|, Na S|, Heo |H, Lee KY. Clinical significance of anti-annexin $\checkmark$ antibody in acute cerebral ischemia. J Neurol Sci. 2011;305(1-2):53-6.

18. Sciascia S, Khamashta MA, Bertolaccini ML. New tests to detect antiphospholipid antibodies: antiprothrombin (aPT) and anti-phosphatidylserine/ prothrombin (aPS/PT) antibodies. Curr Rheumatol Rep. 2014;16(5):415.

19. Atsumi T, leko M, Bertolaccini ML, Ichikawa K, Tsutsumi A, Matsuura E, et al. Association of autoantibodies against the phosphatidylserine-prothrombin complex with manifestations of the antiphospholipid syndrome and with the presence of lupus anticoagulant. Arthritis Rheum. 2000;43(9):1982-93.

20. Tsutsumi A, Hayashi T, Chino Y, Mamura M, Goto D, Matsumoto I, et al. Significance of antiprothrombin antibodies in patients with systemic lupus erythematosus: clinical evaluation of the antiprothrombin assay and the antiphosphatidylserine/prothrombin assay, and comparison with other antiphospholipid antibody assays. Mod Rheumatol. 2006;16(3):158-64.

21. Žigon $P$, Čučnik S, Ambrožič A, Kveder T, Šemrl SS, Rozman B, et al. Detection of antiphosphatidylserine/prothrombin antibodies and their potential diagnostic value. Clin Dev Immunol. 2013;2013:724592. 
22. Sanfelippo MJ, Joshi A, Schwartz S, Meister JA, Goldberg JW. Antibodies to phosphatidylserine/prothrombin complex in suspected antiphospholipid syndrome in the absence of antibodies to cardiolipin or beta-2-glycoprotein I. Lupus. 2013;22(13):1349-52.

23. Fabris M, Giacomello R, Poz A, Pantarotto L, Tanzi N, Curcio F, et al. The introduction of anti-phosphatidylserine/prothrombin autoantibodies in the laboratory diagnostic process of anti-phospholipid antibody syndrome: 6 months of observation. Auto Immun Highlights. 2014;5(2):63-7.

24. Sciascia S, Sanna G, Murru V, Roccatello D, Khamashta MA, Bertolaccini ML. Anti-prothrombin (aPT) and anti-phosphatidylserine/prothrombin (aPS/PT) antibodies and the risk of thrombosis in the antiphospholipid syndrome. A systematic review. Thromb Haemost. 2014;111(2):354-64.

25. Žigon P, Perdan Pirkmajer K, Tomšič M, Kveder T, Božič B, Sodin Šemrl S, et al. Anti-phosphatidylserine/prothrombin antibodies are associated with adverse pregnancy outcomes. J Immunol Res. 2015;2015:975704.

26. Amengual O, Forastiero R, Sugiura-Ogasawara M, Otomo K, Oku K, Favas $C$, et al. Evaluation of phosphatidylserine-dependent antiprothrombin antibody testing for the diagnosis of antiphospholipid syndrome: results of an international multicentre study. Lupus. 2017;26(3):266-76.

27. Nakamura H, Oku K, Amengual O, Ohmura K, Fujieda Y, Kato M, et al. First-line, non-criterial antiphospholipid antibody testing for the diagnosis of antiphospholipid syndrome in clinical practice: a combination of anti- $\beta 2$ -glycoprotein I domain I and anti-phosphatidylserine/prothrombin complex antibodies tests. Arthritis Care Res (Hoboken). 2018;70(4):627-34.

28. Litvinova E, Darnige L, Kirilovsky A, Burnel Y, de Luna G, Dragon-Durey MA. Prevalence and significance of non-conventional antiphospholipid antibodies in patients with clinical APS criteria. Front Immunol. 2018;9:2971.

29. Žigon P, Podovšovnik A, Ambrožič $A$, Tomšič $M$, Hočevar $A$, Gašperšič $N$, et al. Added value of non-criteria antiphospholipid antibodies for antiphospholipid syndrome: lessons learned from year-long routine measurements. Clin Rheumatol. 2019;38(2):371-8.

30. Meijide H, Sciascia S, Sanna G, Khamashta MA, Bertolaccini ML. The clinical relevance of IgA anticardiolipin and IgA anti- $\beta 2$ glycoprotein I antiphospholipid antibodies: a systematic review. Autoimmun Rev. 2013;12(3):421-5.
31. Pericleous C, Ferreira I, Borghi O, Pregnolato F, McDonnell T, Garza-Garcia $A$, et al. Measuring IgA anti- $\beta 2$-glycoprotein I and IgG/lgA anti-domain I antibodies adds value to current serological assays for the antiphospholipid syndrome. PLoS ONE. 2016;11(6):e0156407.

32. Rodríguez-García V, loannou Y, Fernández-Nebro A, Isenberg DA, Giles IP. Examining the prevalence of non-criteria anti-phospholipid antibodies in patients with anti-phospholipid syndrome: a systematic review. Rheumatology (Oxford). 2015;54(11):2042-50.

33. Murthy $V$, Willis R, Romay-Penabad Z, Ruiz-Limón P, Martínez-Martínez $\mathrm{LA}$, Jatwani $\mathrm{S}$, et al. Value of isolated IgA anti- $\beta 2$-glycoprotein I positivity in the diagnosis of the antiphospholipid syndrome. Arthritis Rheum. 2013;65(12):3186-93.

34. Mattia E, Ruffatti A, Tonello M, Meneghel L, Robecchi B, Pittoni M, et al. IgA anticardiolipin and IgA anti- $\beta 2$ glycoprotein I antibody positivity determined by fluorescence enzyme immunoassay in primary antiphospholipid syndrome. Clin Chem Lab Med. 2014;52(9):1329-33.

35. Pelkmans L, de Laat B. Antibodies against domain I of $\beta 2$-glycoprotein I: the one and only? Lupus. 2012;21(7):769-72.

36. Andreoli L, Chighizola CB, Nalli C, Gerosa M, Borghi MO, Pregnolato F, et al. Clinical characterization of antiphospholipid syndrome by detection of IgG antibodies against $\beta 2$-glycoprotein I domain 1 and domain 4/5: ratio of anti-domain 1 to anti-domain 4/5 as a useful new biomarker for antiphospholipid syndrome. Arthritis Rheumatol. 2015;67(8):2196-204.

37. Radin M, Cecchi I, Roccatello D, Meroni PL, Sciascia S. Prevalence and thrombotic risk assessment of anti- $\beta 2$ glycoprotein I domain I antibodies: a systematic review. Semin Thromb Hemost. 2018;44(5):466-74.

38. Mondejar R, González-Rodríguez C, Toyos-Sáenz de Miera FJ, Melguizo-Madrid E, Zohoury N, Mahler M, et al. Role of antiphospholipid score and anti- $\beta 2$-glycoprotein I Domain I autoantibodies in the diagnosis of antiphospholipid syndrome. Clin Chim Acta. 2014;431:174-8.

39. De Craemer AS, Musial J, Devreese KM. Role of anti-domain 1- $\beta 2$ glycoprotein I antibodies in the diagnosis and risk stratification of antiphospholipid syndrome. | Thromb Haemost. 2016;14(9):1779-87. 